\title{
Is Epistemological Disjunctivism the Holy Grail?
}

\author{
Penultimate draft \\ Grazer Philosophische Studien 90, 2014, 157-168.
}

In his highly valuable book, Duncan Pritchard presents a particular account of perceptual knowledge, epistemological disjunctivism (ED). Pritchard argues that this view seems plainly false at first sight, but if it were right, it would represent the "holy grail of epistemology" (1), a view that allows us "to have our cake and eat it too" (3). This prospect motivates Pritchard to develop and defend an account that prima facie might seem simply false. It is disputable whether ED really seems plainly false at first sight or whether this intuition is based on a particular philosophical tradition. However, in this review I will not discuss whether ED is actually true. Rather, I will investigate whether, if true, it has the advantages over rival accounts that Pritchard claims.

One attributed advantage of ED is that it has the potential to dissolve the conflict between epistemic internalism and epistemic externalism, which Pritchard characterizes as follows: epistemic internalism is the view that the crucial epistemic factors for knowledge and justification are internal to agents and, therefore, reflectively accessible to them. According to epistemic externalism, crucial epistemic factors are external and world-linked. Internalism has the advantage of being able to explain the concept of epistemic responsibility, but faces the problem that the epistemic standing of beliefs is not truth-linked. In contrast, externalism can easily establish a connection between the epistemic standing of beliefs and their truth, but faces serious problems in explaining epistemic responsibility. Pritchard claims that ED can overcome this impasse by adopting elements of internalism and externalism. He defines ED as follows:

\section{Epistemological Disjunctivism: The Core Thesis}

In paradigmatic cases of perceptual knowledge an agent, $S$, has perceptual knowledge that $\phi$ in virtue of being in possession of rational support, $\mathrm{R}$, for her belief that $\phi$ which is both factive (i.e., R's obtaining entails $\phi$ ) and reflectively accessible to S. (13)

Thus, ED combines the externalist element of factive support with the internalist element of reflective accessibility. Crucially, ED rejects the standard claim about perceptual knowledge that agents have the same degree of reflectively accessible rational support in good cases of veridical perception and in bad cases of illusions or hallucinations. Rather, ED claims that this support is radically different in the two cases (15).

$\mathrm{ED}$ is a view about perceptual knowledge, not about knowledge in general. In paradigm cases of perceptual knowledge, the particular factive rational support that is also reflectively accessible is 
our "seeing that the target proposition obtains" (14). Pritchard points out that ED is in accordance with "commonsense ways of thinking, and talking, about perceptual reasons" (17) according to which it is normal to say that I know that p, because I see that p. He argues that any philosophical view that is in accordance with commonsense enjoys a default status that is denied to revisionary philosophical views that diverge from common sense. So if ED turns out not to be a complete non-starter as a theoretical position, then it has strong methodological advantages over its revisionary alternatives. Accordingly, Pritchard's main strategy is moderate. He does not want to argue directly for the truth of ED. Rather his objective is to set out what ED amounts to and to explain that ED does not face those prima facie problems that it seems to face. Thereby, Pritchard aims at establishing ED as a possible view that has to be taken seriously into account, especially given its overall attractiveness.

Obviously, the relation between seeing and knowing is crucial for ED. However, Pritchard argues that seeing that $\mathrm{p}$ is neither a particular way of knowing that $\mathrm{p}$ nor is it sufficient for knowing that $\mathrm{p}$ (25). One explanation is that seeing that $\mathrm{p}$ does not entail believing that $\mathrm{p}$, whereas knowing that $\mathrm{p}$ does. However, seeing that $\mathrm{p}$ still guarantees that one is in a good position for knowing that p; a correct analysis, I think.

Pritchard presents a taxonomy of six different cases for exploring the relation between seeing and perceptual knowledge in more detail (29). Good + is the case of truly believing that p based on seeing that $\mathrm{p}$ in the absence of any defeater. In this case, the epistemic conditions are objectively and subjectively good. Good + is a case of veridical perception for Pritchard, where S sees that p and knows that $\mathrm{p}$. In the following five cases, $\mathrm{S}$ does not know that $\mathrm{p}$ anymore. In the second case, Good, S sees that p but is or should be in possession of a defeater for p. Here, the epistemic conditions are still objectively good, but subjectively bad. In case Good, S still sees that p, but does not know that $\mathrm{p}$. In the third case, Bad, the circumstances of perception are objectively bad, but subjectively good. Such a case occurs, for example, if one is confronted with a real barn in fakebarn county. In the fourth case $\mathrm{Bad}+$, the epistemic conditions are neither objectively nor subjectively good. In all four of these cases the perception is veridical, but the epistemic circumstances vary. In the last two cases, $B a d++$ and $B a d+++$, the perception is not veridical. In case $\mathrm{Bad}++$ the epistemic conditions are at least subjectively good, whereas in Bad+++ $\mathrm{S}$ also is or should be aware of a defeater.

Epistemologists often only distinguish between good cases of veridical perception and bad cases, without developing a more fine grained taxonomy. In this respect, Pritchard's taxonomy has its merits. However, I do not find it entirely plausible. In case Good, S sees that p, but does not know that $\mathrm{p}$, because $\mathrm{S}$ is or should be aware of a defeater. For example, if $\mathrm{S}$ is not in fake barn county but a normally trustworthy person told her that she is. In case Bad, S actually is in bad epistemic 
conditions like in fake barn county. In both Good and Bad, S's perception is veridical, i.e. she is confronted with a barn, but only in case Good does S see that there is barn. I find this distinction awkward. It is more plausible that $\mathrm{S}$ sees in both cases that there is a barn. Whether $\mathrm{S}$ actually is in barn county only affects S's knowledge or justification. However, not much seems to hinge on this taxonomy. Pritchard could easily adapt it without weakening his point that seeing is not sufficient for knowing, though he would have to weaken his claim about the epistemic position one is in when seeing that $\mathrm{p}$. If S can also see a barn in fake barn county, then S's seeing that p can fail to constitute knowledge for these objective reasons as well. However, this seems like a terminological discussion.

Pritchard's Epistemological Disjunctivism consists of three parts. Part one sets out the position of ED and outlines three main prima facie problems that conflict with the view: the access problem, the basis problem and the distinguishability problem. The access problem takes the form of a reductio argument against ED according to which ED entails the implausible claim that one can have knowledge of empirical propositions by a priori reflection alone. Here is how this problem arises according to Pritchard. Suppose that the rational support for my belief that Ann is in the office is that I see her in the office, which is, according to ED, reflectively accessible. Given that I know that seeing that $\mathrm{p}$ entails $\mathrm{p}$, it seems that I can deductively conclude from a priori reflection alone that Ann is in her office.

I do not find the access problem convincing, since it seems obvious that, according to ED, seeing that $\mathrm{p}$ as a premise of the access problem is more than what there is accessible by reflection alone. However, Pritchard argues sophisticatedly against the access problem. He concludes that the only point it can make is that in case of veridical perception, $\mathrm{S}$ can know by reflection alone that her reason for believing that $\mathrm{p}$ is the factive empirical reason $\mathrm{R}$ (her seeing that $\mathrm{p}$ ) which entails p. However, this conclusion is far weaker than the conclusion of the original access problem. Pritchard's argumentation is careful and precise, but given the unconvincing nature of the access problem, this argumentation itself will not convince many critics that ED is true.

The second prima facie problem for ED that Pritchard diagnoses is the basis problem. This problem arises from the question of how seeing can provide the basis of knowing, if seeing is a form of knowing. Pritchard's response to this problem is based on his view about the relation between seeing and knowing. Seeing is not a particular kind of knowledge, and, therefore, the basis problem is neutralized. Again, I see nothing wrong with Pritchard's response, but I also do not see the impact of the basis problem for ED.

The third problem is the distinguishability problem. ED accepts that veridical perception and hallucinations are by assumption introspectively indiscriminable. The problem arising for ED is how factive rational support can be reflectively accessible, given that they are introspectively 
indiscriminable. Part two of Epistemological Disjunctivism is almost entirely devoted to the distinguishability problem. It is the hardest problem for ED according to Pritchard. I agree, moreover I think it is intuitively the most appealing one.

Pritchard argues that when it comes to distinguishability, we have to differentiate between various principles. The following two principles are the most interesting ones:

\section{The Discrimination Principle}

If $S$ has perceptual knowledge that $\phi$, and $S$ knows that another (known to be inconsistent) alternative $\psi$ does not obtain, then $S$ must be able to perceptually discriminate between the object at issue in $\phi$ and the object at issue in $\psi$. (73)

\section{The Favouring Principle}

If $S$ (i) knows that $\phi$, and (ii) knows that $\psi$, and (iii) knows that $\phi$ entails $\psi$, then $S$ has better evidence in support of her belief that $\phi$ than for believing that not- $\psi$. (76)

Pritchard correctly argues that the discrimination principle puts stronger requirements on knowledge than the favouring principle. The illustrative example he uses is Dretske's zebra case. $\mathrm{S}$ can have favoring epistemic support for her belief that the animal in the pen is a zebra and not a painted mule (e.g. by having background knowledge about the trustworthiness of the zoo administration) without having the capacity to perceptually discriminate between zebras and painted mules. In this case, $S$ fulfills the favouring principle but not the discrimination principle. Pritchard argues that the discrimination principle can be dismissed as too strong. The reason for our mistaken intuition in the zebra case is the false assumption that the missing evidence is discriminatory evidence, so Pritchard argues. Analogously, ED is not the claim that $\mathrm{S}$ can introspectively distinguish between case Good + and the bad cases. Rather it is the weaker claim that these cases are reflectively distinguishable. Importantly, Pritchard argues that this view is not based on ED, and should be acceptable to defenders of alternative views. Pritchard analysis of these cases is convincing, but not new. Vogel's (1990) influential work that comes to a similar conclusion could be cited at that point.

Part three of Epistemological Disjunctivism is entirely devoted to the skeptical problem. Pritchard points out that there is an essential difference between the zebra case and skepticism. In the zebra case we can know that the animal in the pen is a zebra and not a painted mule if we have additional and independent rational support. We need not have the capacity to perceptually discriminate between zebras and painted mules. However, the skeptic calls everything into question. Therefore, we cannot appeal to this kind of independent background knowledge for ruling out the skeptical alternative of global hallucination according to Pritchard. 
One way ED could respond to skepticism is 'simple-minded epistemological disjunctivist NeoMooreanism' which argues along the following lines: In case Goodt, S knows that p because S sees that $\mathrm{p}$. Given that S's rational support for $\mathrm{p}$ entails that $\mathrm{p}$, and that $\mathrm{S}$ knows that $\mathrm{p}$ entails that $\mathrm{S}$ is not a brain in vat deceived in falsely believing that $\mathrm{p}(\sim \mathrm{BIV}), \mathrm{S}$ can conclude by deduction that $\sim$ BIV and thereby reflectively distinguish $\mathrm{p}$ from BIV. The way I understand this inference is:

\author{
Simple-minded ED \\ I see that $\mathrm{p}$ \\ Therefore, I know that $\mathrm{p}$ \\ I know that p entails $\sim$ BIV \\ Therefore, I know that $\sim$ BIV
}

Pritchard dismisses simple-minded ED by incorporating a defeater condition. He argues that the orthodox view mistakenly treats all error possibility equally, no matter whether they are epistemically motivated or just raised (125). It is disputable, whether this really is the orthodox view about error possibilities. Pritchard objects that we only need to appeal to additional evidence if the error possibility is motivated. If one buys into Pritchard's distinction, then the solution to the skeptical problem is easy at hand. Radical skeptical hypotheses are just raised but not epistemically motivated (126). Thus, one need not appeal to independent rational support to reject them. Pritchard's anti-skeptical strategy can be summarized as follows:

\title{
Pritchard's ED
}

I see that $\mathrm{p}$

If there are no epistemically motivated error possibilities, then if I see that $\mathrm{p}$, then I know that $\mathrm{p}$

There are no epistemically motivated error possibilities

Therefore, I know that $\mathrm{p}$

p entails $\sim$ BIV

Therefore, I know that $\sim$ BIV

Pritchard's dismissal of the simple-minded ED seems puzzling and unmotivated. If one accepts that the factive rational support is reflectively accessible as ED does, then why shouldn't one utilize it the way simple-minded ED suggests? Admittedly, it is a familiar externalist move to incorporate a defeater condition into the account of knowledge or justification as Goldman's (1979) original formulation of process reliabilism also suggests, but this connection is neither motivated by process reliabilism nor by ED itself.

Notably, Prichard's anti-skeptical strategy mirrors the internalistic strategy of dogmatism as defended by Huemer (2000) and Pryor (2000 and 2004). They argue that, in absence of any 
defeaters, one's experience as of $\mathrm{p}$ gives one prima facie justification that $\mathrm{p}$. This dogmatist strategy takes the following form:

\section{Dogmatism}

I have an experience as of $\mathrm{p}$

In absence of any defeaters, if I have an experience as of $\mathrm{p}$, then I am justified to believe that $\mathrm{p}$

There are no defeaters

Therefore, I am justified to believe that $\mathrm{p}$

I know that $\mathrm{p}$ entails $\sim \mathrm{BIV}$

Therefore, I am justified to believe that $\sim$ BIV

Because of Pritchard's treatment of defeaters, he adopts the dogmatist strategy, except he replaces the internalistic concepts of "experience" and "justification" with the factive concepts of "seeing" and "knowing". One might argue that the factivity of the rational support in the case of ED makes the difference to dogmatism. However, this potential difference does not affect the dialectical potential of the two accounts.

After presenting his anti-skeptical response, Pritchard investigates the dialectical situation concerning skepticism. Pritchard distinguishes between overriding and undercutting anti-skeptical strategies. Overriding anti-skeptical strategies concede that the skeptical intuition is plausible but claim that there are independent theoretical grounds for rejecting it, since intuitions are only defeasible guides to truth (132). Undercutting anti-skeptical strategies, in contrast, show that, properly understood, the skeptical claims are not intuitive at all. When it comes to analyzing the dialectic between the skeptic and the anti-skeptic, undercutting strategies are preferable to overriding ones. Moreover, Pritchard claims that ED is clearly undercutting. He admits that there might exist various intermediate cases between overriding and undercutting skeptical strategies, but he assumes that the distinction is clear enough for his purposes (133). I doubt that this is the case.

Let's compare ED to internalistic and externalistic alternatives with respect to (1) knowing that p, (2) knowing that $\sim$ BIV and (3) higher-order knowledge that one knows that p. I pick dogmatism as an internalistic account and process reliabilism as an externalistic one, although other externalistic accounts of knowledge like safety or certain virtue epistemological account will deliver similar results. Pritchard argues that the skeptical intuition is based on internalistic intuitions. Therefore, externalistic anti-skeptical strategies are by their nature overriding, because they reject internalism for independent theoretical reasons (133). Thus, we should at least find a clear criterion for distinguishing the dialectical features of ED from those of process reliabilism. Let's see, first, how these three accounts can explain the possibility of perceptual knowledge: 


\title{
Perceptual knowledge for ED
}

$\mathrm{S}$ has perceptual knowledge that $\mathrm{p}$ iff $\mathrm{S}$ sees that $\mathrm{p}$ and there are no epistemically motivated defeaters for $\mathrm{p}$

\section{Perceptual knowledge for dogmatism}

$\mathrm{S}$ has perceptual knowledge that $\mathrm{p}$ iff $\mathrm{S}$ has an experience as of $\mathrm{p}$ and believes that $\mathrm{p}$ and there do not exist any defeaters for $\mathrm{p}$ (and if the further necessary conditions for converting justified beliefs into knowledge are fulfilled)

\section{Perceptual knowledge for process reliabilism}

$\mathrm{S}$ has perceptual knowledge that $\mathrm{p}$ iff $\mathrm{S}$ truly believes that $\mathrm{p}$ based on a reliable process of perception (and if there do not exist any defeaters for $\mathrm{p}$ and if the further necessary conditions for converting justified true beliefs into knowledge are fulfilled)

Obviously each of these three accounts of knowledge offers an explanation of how perceptual knowledge is possible that is crucially based on a more general account of knowledge.

How can we know according to these accounts that $\sim$ BIV? One way is simply by deduction as follows:

$\mathrm{p}$

Therefore, I am not a BIV deceived in falsely believing that $\mathrm{p}$

This entailment relation holds if the anti-skeptical proposition is understood as $\sim((\mathrm{I}$ am a BIV that believes that p) \& p). The three compared knowledge accounts all seem to license this kind of deductive knowledge.

One might argue with Klein (2004) that this conclusion is just equivalent to the disjunction $\sim(\mathrm{I}$ am a BIV that believes that $\mathrm{p}) \vee \mathrm{p}$ which does not tell us anything informative about the conditions of our perception. So one might search for a stronger anti-skeptical thesis like "I correctly experience and believe that $p$ " with the underlying formal structure $E(p) \& B(p) \& p$. According to dogmatism, $\mathrm{S}$ can draw the following deductive inference:

\section{Knowledge that $\sim$ BIV for dogmatism}

$\mathrm{p}$ (by having an experience as of $\mathrm{p}$ )

I have an experience as of $\mathrm{p}$ and I believe that $\mathrm{p}$ (by introspection)

Therefore, I correctly experience and believe that $\mathrm{p}$ (by deduction)

Therefore, I am not a BIV hallucinating that $\mathrm{p}$ (by deduction)

Process reliabilists can use the same inference, except that the belief in $\mathrm{p}$ must result from a reliable belief forming process. For ED, the inference takes simply the following form:

\author{
Knowledge that $\sim$ BIV for ED \\ I see that $\mathrm{p}$ \\ Therefore, I am not a BIV hallucinating that $\mathrm{p}$
}


Again, all three accounts of knowledge license knowledge in the stronger denial of the skeptical hypotheses via inference from $p$ itself.

How can $\mathrm{S}$ acquire a more demanding higher-order knowledge that she has perceptual knowledge? In this case, $\mathrm{S}$ has to know that the conditions for knowledge that these accounts propose are fulfilled and that these conditions are sufficient for knowledge. The inferences take the following line:

Higher-order knowledge for ED

(1) I see that $\mathrm{p}$ (by reflection)

(2) There are no epistemically motivated defeaters for $\mathrm{p}$ (by reflection)

(3) if (1) and (2) are true, then I have perceptual knowledge that $\mathrm{p}$ (by philosophical argumentation)

(4) Therefore, I have perceptual knowledge that $\mathrm{p}$ (by deduction)

\section{Higher-order knowledge for dogmatism}

(1) I have an experience as of $\mathrm{p}$ (by introspection)

(2) There are no defeaters for $\mathrm{p}$ (by reflection)

(3) If (1) and (2) are true (and further conditions for transforming justified beliefs into knowledge are fulfilled), then I have perceptual knowledge that $\mathrm{p}$ (by philosophical argumentation)

(4) Therefore, I have perceptual knowledge that $\mathrm{p}$ (by deduction)

So far, I do not see any crucial difference between the dialectical capacities of ED and of dogmatism as ED's purely internalistic counterpart. Pritchard argues that ED is dialectically superior to other accounts because of its undercutting nature. Notably Pryor $(2004,362)$ thinks that Moorean arguments based on dogmatism are "persuasively crippled", but that their justificatory structure is flawless. Thus, there is disagreement about the dialectical capacities of very similar accounts. I doubt that ED's dialectical position is strong. Specifically, I do not see why $\mathrm{ED}$ is more theoretically attractive than dogmatism.

For process-reliabilism, higher-order knowledge is achieved slightly differently. Vogel (2000) has pointed out that if process reliabilism is true, then one can acquire knowledge about the reliability of a source (and therefore higher-level knowledge) via bootstrapping, i.e., by basing it on knowledge delivered by this source. In the case of knowledge about the reliability of one's own perception, bootstrapping takes the following form:

Higher-order knowledge for process reliabilism

(1) $\mathrm{p}$ (reliable process via perception)

(2) I believe that $\mathrm{p}$ based on perceiving that $\mathrm{p}$ (reliable process via introspection)

(3) My perception that $\mathrm{p}$ and my belief that $\mathrm{p}$ are correct (logical inference)

(4) Repeat

(5) My perception is reliable (induction)

(6) If my perception is reliable, then my true beliefs based on perception constitute knowledge (by philosophical argumentation) 
(7) Therefore, I have perceptual knowledge that $\mathrm{p}$ (by deduction)

Bootstrapping as a process of acquiring higher-order knowledge is usually regarded as a problem for externalist accounts, not as an advantage. Vogel argues that process reliabilism sanctions every step of bootstrapping. However, since bootstrapping is an obviously flawed reasoning process, according to Vogel, process reliabilism is false. Thus, Vogel uses bootstrapping as a reductio argument against process reliabilism. Cohen (2002) argues more generally that any account of knowledge that allows one to have knowledge via a source without having prior knowledge about the reliability of the source suffers from the "easy knowledge problem". This problem takes the following form for a dogmatist response to the skeptic.

(1) I have an experience as of $\mathrm{p}$

(2) Therefore, $p$

(3) Therefore, I am not a BIV having a hallucination as of $\mathrm{p}$

Thus, process reliabilism and dogmatism both face the problem of easy knowledge in one way or another. One might suspect that this gives ED a crucial advantage over its rival accounts. However, I doubt that this is the case. Take the following inference from ED:

(1) I see that $\mathrm{p}$

(2) Therefore, I am not a BIV having a hallucination as of $\mathrm{p}$

I doubt that those who criticize process reliabilism and dogmatism for facing the easy knowledge problem find this inference a more convincing anti-skeptical move.

To sum up: ED, dogmatism and process reliabilism provide an explanation for how we can have perceptual knowledge. They also allow for knowledge that $\sim$ BIV via deduction from perceptual knowledge. The ways of acquiring higher-order knowledge about perceptual knowledge are different but they are all based on perceptual knowledge. However, ED can provide a far more natural explanation for higher-order knowledge than dogmatism or process reliabilism. I think this is its crucial advantage. Nevertheless, the three strategies seem dialectically equally overriding or undercutting. Given this diagnosis, I do not see the respect in which externalist anti-skeptical strategies should be overriding in nature whereas ED is undercutting.

The way we can acquire knowledge that $\sim$ BIV and higher-order knowledge based on perceptual knowledge is somehow unsatisfactory. I think the underlying explanation is that the skeptic not only claims that we neither know $\sim$ BIV nor have perceptual knowledge. Rather, she suggests that we do not have perceptual knowledge because we do not know that $\sim$ BIV. The skeptic thereby implicitly assumes that we need to have knowledge that $\sim \mathrm{BIV}$ in the first place in order to have any kind of perceptual knowledge. This view is conservatism, as opposed to liberalism, about 
perception. Conservative anti-skeptics like Vogel (1990a) think that we have the kind of necessary a priori knowledge that $\sim$ BIV. Importantly, the skeptic is also a conservative but she rejects the view that we have any a priori justification for $\sim$ BIV. By making its conservative presupposition explicit, we can formulate skepticism as follows:

\section{Conservative skepticism}

We need to have prior knowledge that $\sim \mathrm{BIV}$ in order to have perceptual knowledge that p.

Liberalism about perception allows for basic perceptual knowledge to take different forms. Process reliabilism licenses basic knowledge from any reliable source. Pryor, as a dogmatist, is a liberal about perception but thinks that other sources should be treated differently. ED is a view only about perceptual knowledge and does not make any claims about other potential knowledge sources. The three accounts reply to conservative skepticism as follows:

\section{ED's response to conservative skepticism}

No we don't. We only need this kind of prior knowledge if there are epistemically motivated defeaters.

\section{Dogmatism's response to conservative skepticism}

No we don't. In the absence of defeaters, our experience as of $\mathrm{p}$ gives us prima facie justification for believing that $\mathrm{p}$.

\section{Process reliabilism's response to conservative skepticism}

No we don't. We can know that $\mathrm{p}$ if our perceptual apparatus reliably produces true beliefs.

How can we characterize the dialectic between these three accounts and conservative skepticism? Process reliabilists, dogmatists and those who defend ED reject conservatism on the basis of liberal views concerning perceptual knowledge or knowledge in general. They do not provide any independent argument that conservatism is false for intrinsic reasons. Picking up Pritchard's terminology, they override conservatism about perception rather than undercut it. Thus, ED, process reliabilism and dogmatism might undercut skepticism understood as the general claim that we neither have perceptual knowledge nor knowledge that $\sim$ BIV. However, they only override conservative skepticism. Thus, the crucial point of dispute between ED and skepticism is the more general one between liberalism and conservatism, and the dialectic at that level can only be overriding, not undercutting. Again, ED and its rival accounts like dogmatism and process reliabilism are in the same boat.

Where does this leave us dialectically? I do not see any dialectical advantage for ED over alternative liberal accounts. Thus, ED is not the Holy Grail for the skeptical problem. Either the 
Holy Grail is simply an account of basic knowledge, in which case any account allowing basic knowledge is an instance of it or it is a conservative anti-skeptical strategy or the search has to go on.

Acknowledgements The research was funded by the Austrian Science Fund (FWF): J 3174G15.

Guido Melchior (University of Graz)

\section{References}

Cohen, Stewart 2002: "Basic Knowledge and the Problem of Easy Knowledge". Philosophy and Phenomenological Research 65(2), 309-329.

Goldman, Alvin I. 1979: "What Is Justified Belief?". In: George Pappas (ed), Justification and Knowledge. Dordrecht: Reidel, 1-23.

Huemer, Michael 2000: "Direct Realism and the Brain-in-a-Vat Argument". Philosophy and Phenomenological Research 61(2), 397-413.

Klein, Peter 2004: "Closure Matters: Academic Skepticism and Easy Knowledge". Philosophical Issues 14(1), 165-184.

Pryor, James 2000: “The Skeptic and the Dogmatist". Noûs 34(4), 517-549.

---- 2004: “What's Wrong with Moore's Argument?”. Philosophical Issues 14(1), 349-378.

Vogel, Jonathan 1990: “Are There Counterexamples to the Closure Principle?" In: Michael David Roth \& Glenn Ross (eds.), Doubting: Contemporary Perspectives on Skepticism. Dordrecht: Kluwer, 1329.

--- 1990a: “Cartesian Skepticism and Inference to the Best Explanation.” Journal of Philosopby 87, 658-66.

---- 2000: "Reliabilism Leveled". The Journal of Philosophy 97(11), 602-623. 